\title{
Catalytic liquefaction of wood for production of biocrude
}

\author{
Ramakrishna Jogi $^{1, *, \#}$, Päivi Mäki-Arvela ${ }^{1, *, \$}$, Pasi Virtanen ${ }^{1}$ and Jyri-Pekka Mikkola ${ }^{1,2}$ \\ ${ }^{1}$ Laboratory of Industrial Chemistry and Reaction Engineering, Johan Gadolin Process Chemistry Centre, \\ Åbo Akademi University, Finland. ${ }^{2}$ Technical Chemistry, Department of Chemistry, Chemical-Biological \\ Centre, Umeå University, Sweden.
}

\begin{abstract}
Production of biofuels from second-generation biomass gives us an opportunity to minimise the dependence on fossil resources. Woody biomass is a valuable energy resource mainly composed of underutilized hemicellulose and lignin. The third fraction, i.e. residual cellulose from wood liquefaction is frequently used as a starting material in pulping and packaging industry. The catalytic liquefaction of woody biomass, which can be performed even without drying of feedstock to produce biocrude, is a promising route to biofuels and fine chemicals. This work emphasizes the use of heterogeneous catalysts in wood liquefaction to produce biocrude containing both phenolic compounds and sugars. The main parameters discussed are wood type, catalyst selection and reaction conditions, such as gas atmosphere, solvent, temperature, pressure and feedstock particle size. Several metals (Pd, Ru, $\mathrm{Ni}, \mathrm{Co}, \mathrm{Mo}, \mathrm{Fe}$ ) supported on active carbon, alumina and zeolites have been applied in wood liquefaction. In addition to heterogeneous catalysts, also co-catalysts, such as homogeneous acids and metal salts have been utilized to promote, in particular, lignin depolymerization. The liquid phase product distribution including sugars, phenolic monomers, dimers and oligomers over different catalysts will be discussed. Different catalytic
\end{abstract}

\footnotetext{
*Corresponding authors

\#ramsjogi@gmail.com

\$pmakiarv@abo.fi
}

approaches will also be elucidated. Finally, future research needs and process feasibility will also be summarized.

KEYWORDS: catalytic liquefaction, hydrothermal liquefaction (HTL), wood liquefaction, hydrogen atmosphere, noble and non-noble metal catalyst.

\section{Introduction}

Lignocellulosic (wood) biomass is one of the essential renewable reserve and organic carbon supplies in the world [1-3]. It absorbs atmospheric $\mathrm{CO}_{2}$ during photosynthesis and is proficient in addressing both the concerns of enriched domestic fuel production and a reduction of greenhouse gas emissions [4]. Among the various renewable resources, lignocellulosic woody biomass is a viable option because some of the trees can also survive under drastic conditions [5, 6]. Moreover, utilization of lignocellulosic material as a feedstock for the production of renewable green fuel and fine chemicals is more adaptable. If harvested sustainably, the lignocellulosic feedstock has the potential to play an important role in determining the world's energy supply in future [7]. Hence, increasing the alertness of the depletion of fossil fuel carbon stocks, and attentiveness in biomass transformation have shown a continuous rapid increase and have resulted in intensive research in both academia and industry. Among various biomass feedstocks (such as edible, non-edible oils, algae, etc.) terrestrial lignocellulosic biomass has a paramount importance, since it is present in large quantities in both woody and herbaceous 
plant materials [8]. Lignocellulosic material is primarily a composite of three oxygen-containing high molecular weight polymers, namely cellulose, hemicellulose, and lignin. It also contains minor amounts of terpenes, oils and inorganic (ash) materials [9]. In novel biorefineries, a major endeavour is the transformation of lignocellulosic biomass into biofuels and fine chemicals. Furthermore, some of the lignocellulose-derived molecules have been used as starting materials to be further converted into the specific type of fuel components [10-13] such as alkanes and cycloalkanes.

Biocrude can be produced through biochemical and thermochemical techniques [14-16]. Among those techniques, thermochemical techniques are most efficient methods to transform lignocellulosic woody biomass into crude. Principally, in the thermochemical approach, long-chain biopolymers, i.e. cellulose, hemicellulose and lignin molecules, are breaking down into small molecules at elevated temperatures and pressures. Thermal conversion techniques have the potential to produce high liquid yields directly from biomass. The performance of these techniques depends on the process conditions such as temperature, pressure, residence time, solvent medium and catalysts employed [17, 18]. In this work, the processes are defined enlisting the reaction conditions and detailed information concerning the catalytic materials. In particular, direct liquefaction processes, such as pyrolysis and catalytic liquefaction or hydrothermal liquefaction (HTL) techniques are reviewed. The main emphasis in this work is on HTL and correlation of process conditions with the product distribution and desired product quality. Some reviews can already be found $[19,20]$ focusing on feedstock, liquefaction technology, target products, degradation mechanism of each biomass components, and technology developments concerning the liquefaction processes; However, the catalyst selection is scarcely addressed. In this mini-review, the main topics are selection of catalyst, catalyst reuse and optimization of reaction conditions. Finally, future prospects for wood liquefaction are summarized.

Pyrolysis is the thermal decomposition process of biomass in the absence of oxygen using a short residence time. The resulting several different products are formed during pyrolysis including vapors, liquids, and solids (coke and ash). The liquid fraction of the product, termed as bio-oil or pyrolysis oil, can be used for production of fuels and as a source for various platform molecules. The pyrolysis performed at elevated temperature and pressure for production of biocrude is termed as fast pyrolysis process in which the heating rate and temperatures are high (10 to $200{ }^{\circ} \mathrm{C} / \mathrm{s}$ and 500 to $900{ }^{\circ} \mathrm{C}$, respectively) along with short residence times ( 0.5 to $5 \mathrm{sec}$ ), whereas slow pyrolysis is characterized by slower heating rates, moderately long solid as well as vapor residence times equal to $0.1^{\circ} \mathrm{C}$ to $1^{\circ} \mathrm{C}$ and 5-30 min, respectively. In fact, slow pyrolysis process aims mainly at the production of charcoal and not bio-oil [21]. One notable obstacle concerning the bio-oil is its instability and corrosive properties. During fast pyrolysis, the char/ash formation and corrosiveness of the product may cause challenges. Char in bio-oil can enhance polymerization reactions inside the liquid product, which results in increased viscosity of the product oil [22-24]. Hence, bio-oil quality is related to its composition.

Hydrothermal liquefaction (HTL) or catalytic liquefaction of lignocellulose (wood) material for production of biocrude is another recently intensively studied method [25-47]. The liquefaction process is analogous to the formation of fossil fuels under earth crust over millions of years. According to the open literature, the first catalytic liquefaction process in plant scale was demonstrated in early 1970's at the U.S. Bureau of Mines Pittsburgh Energy Research Center (PERC) [25]. The process was subject to utilize dried wood biomass (sieved to about $300 \mu \mathrm{m}$ ) and it was blended with plant-recycled oil over aqueous $\mathrm{Na}_{2} \mathrm{CO}_{3}$ catalyst at $350{ }^{\circ} \mathrm{C}$, in the presence of carbon monoxide gas for 25 min runtime [25] resulting in crude bio-oil and flue gases.

\section{Catalyst selection for production of biocrude via hydrothermal liquefaction of wood}

The first phase in biomass liquefaction is to produce biocrude which contains phenolic products and sugars. They are, consequently, processed further into valuable fuel components and fine 
chemicals. The catalytic liquefaction of wood is mainly focused on degradation of internal wood components such as lignin and hemicellulose, while cellulose remains stable. Various catalytic materials have been used to produce biocrude such as Pd [27], Pt [35], Ru [27], Ni [28], Co [38], CoMo [32], and Fe [29, 30] supported on active carbon [27], alumina [28] and zeolite [27, 28, 29, $30,31,44]$. Upon reductive wood liquefaction, the main desired products are phenolic monomers [27-32, 38, 44]. The role of metal is crucial in this process, as it enables the formation of monomeric phenolic products and determines which types of products are formed (Table 1). The role of the metal is discussed in more detail below.
Non-noble metal catalysts, such as $\mathrm{Ni}[26,28]$, cobalt [38] and iron [29, 30] have been used in wood liquefaction. These catalysts are less expensive than noble metal catalysts. Lewis acidic $\mathrm{Ni} / \mathrm{Al}_{2} \mathrm{O}_{3}$ was used upon birch liquefaction in methanol [28]. In this work, it was also noted that wood liquefaction occurs non-catalytically in the absence of any catalyst producing, however, mainly large oligomers [28]. These results [28] revealed that ether bond cleavage can occur in the presence and absence of $\mathrm{Ni} / \mathrm{Al}_{2} \mathrm{O}_{3}$ catalyst since lignin oil yield seems to be same when a catalyst is present and in the absence of any catalyst (Scheme 1). In the presence of a catalyst, however, more monomers were produced [28]. The presence

Table 1. Liquefaction of wood biomass over heterogeneous catalysts.

\begin{tabular}{|c|c|c|c|c|c|c|}
\hline Entry & $\begin{array}{l}\text { Feedstock } \\
\quad \text { (size) }\end{array}$ & $\begin{array}{l}\text { Solvent } \\
\text { medium }\end{array}$ & $\begin{array}{l}\text { Catalytic } \\
\text { material }\end{array}$ & $\begin{array}{l}\text { Liquefaction } \\
\text { conditions }\end{array}$ & $\begin{array}{l}\text { Yield } \\
(\%)\end{array}$ & Ref. \\
\hline 1 & $\begin{array}{c}\text { Birch } \\
(<420 \mu \mathrm{m})\end{array}$ & Water & $\mathrm{Ni}-\mathrm{W}_{2} \mathrm{C} / \mathrm{AC}$ & $\begin{array}{c}235^{\circ} \mathrm{C}, 4 \mathrm{~h}, \\
60 \text { bar } \mathrm{H}_{2}, 1000 \mathrm{rpm}\end{array}$ & $46.5^{\mathrm{a}}$ & {$[26]$} \\
\hline 2 & $\begin{array}{c}\text { Birch } \\
(250-500 \mu \mathrm{m})\end{array}$ & Methanol & $\mathrm{Ni} / \mathrm{Al}_{2} \mathrm{O}_{3}$ & $\begin{array}{c}200{ }^{\circ} \mathrm{C}, 3 \mathrm{~h}, \\
30 \text { bar } \mathrm{H}_{2}, 750 \mathrm{rpm}\end{array}$ & $\begin{array}{l}44^{\mathrm{a}}, \\
87^{\mathrm{b}}\end{array}$ & [28] \\
\hline 3 & $\begin{array}{l}\text { Straw: wood: grass } \\
\text { mixture }\end{array}$ & Tetraline & Raney Ni & $\begin{array}{c}330^{\circ} \mathrm{C}, 15 \mathrm{~min}, \\
16 \text { bar } \mathrm{H}_{2}, 1000 \mathrm{rpm}\end{array}$ & $18^{\mathrm{c}}$ & [31] \\
\hline 4 & $\begin{array}{l}\text { Poplar } \\
(2 \mathrm{~mm})\end{array}$ & $\begin{array}{c}\text { 2-proponal: } \\
\text { water } \\
(7: 3 \mathrm{v} / \mathrm{v})\end{array}$ & Raney Ni & $\begin{array}{c}220^{\circ} \mathrm{C}, 3 \mathrm{~h} \text {, } \\
\text { no external } \mathrm{H}_{2}\end{array}$ & $\begin{array}{l}87^{\mathrm{b}} \\
26^{\mathrm{c}}\end{array}$ & [34] \\
\hline 5 & $\begin{array}{c}\text { Birch } \\
(\leq 250 \mu \mathrm{m})\end{array}$ & $\begin{array}{l}\text { Ethanol: water } \\
\qquad(5: 5 \mathrm{v} / \mathrm{v})\end{array}$ & $\begin{array}{c}\text { Co- } \\
\text { Phenanthroline/C, } \\
\text { HCOOH } \\
\text { (co-solvent) }\end{array}$ & $\begin{array}{l}200^{\circ} \mathrm{C}, 4 \mathrm{~h} \text {, } \\
\text { no external } \mathrm{H}_{2}\end{array}$ & $34^{\mathrm{a}}$ & [38] \\
\hline 6 & $\begin{array}{c}\text { Pine } \\
(300-600 \mu \mathrm{m})\end{array}$ & Tetraline & $\mathrm{Co}-\mathrm{Mo} / \gamma-\mathrm{Al}_{2} \mathrm{O}_{3}$ & $\begin{array}{c}400^{\circ} \mathrm{C}, 2 \mathrm{~h}, \\
100 \text { bar } \mathrm{H}_{2}\end{array}$ & $36^{\mathrm{c}}$ & {$[32]$} \\
\hline 7 & $\begin{array}{l}\text { Jack pine } \\
(<800 \mu \mathrm{m})\end{array}$ & Ethanol & $\mathrm{FeSO}_{4}$ & $\begin{array}{c}350^{\circ} \mathrm{C}, 40 \mathrm{~min}, \\
50 \mathrm{bar}_{2},\end{array}$ & $63^{c}, 88^{e}$ & [29] \\
\hline 8 & $\begin{array}{c}\text { Birch } \\
(<100 \mathrm{~mm})\end{array}$ & Ethanol & Fe/H-Beta-150 & $\begin{array}{c}243^{\circ} \mathrm{C}, 1 \mathrm{~h}, \\
5 \text { bar } \mathrm{H}_{2}, 300 \mathrm{rpm}\end{array}$ & $\begin{array}{l}25^{\mathrm{c}} \\
68^{\mathrm{d}}\end{array}$ & [30] \\
\hline 9 & $\begin{array}{c}\text { Birch } \\
\text { (saw dust) }\end{array}$ & Methanol & $\mathrm{Ru} / \mathrm{C}$ or $\mathrm{Pd} / \mathrm{C}$ & $\begin{array}{c}250{ }^{\circ} \mathrm{C}, 3 \mathrm{~h}, \\
30 \mathrm{bar}_{2}, 700 \mathrm{rpm}\end{array}$ & $\begin{array}{c}48^{\mathrm{a}}, 49^{\mathrm{a}} \\
90^{\mathrm{b}} \\
90^{\mathrm{b}}\end{array}$ & [27] \\
\hline 10 & $\begin{array}{c}\text { Birch } \\
(125-300 \mu \mathrm{m})\end{array}$ & $\begin{array}{c}\text { Methanol: } \\
\text { water } \\
(1: 2 \mathrm{~mol} / \mathrm{mol})\end{array}$ & $\mathrm{Pt} / \gamma-\mathrm{Al}_{2} \mathrm{O}_{3}$ & $\begin{array}{c}230{ }^{\circ} \mathrm{C}, 3 \mathrm{~h}, \\
30 \text { bar } \mathrm{N}_{2}, 500 \mathrm{rpm}\end{array}$ & $46^{\mathrm{a}}$ & [35] \\
\hline
\end{tabular}

${ }^{\mathrm{a}}$ :monomer phenolic yield, ${ }^{\mathrm{b}}$ :delignification yield, ${ }^{\mathrm{c}}$ :bio-oil yield, ${ }^{\mathrm{d}}$ :phenolic compounds, ${ }^{\mathrm{e}}$ :biomass conversion. 


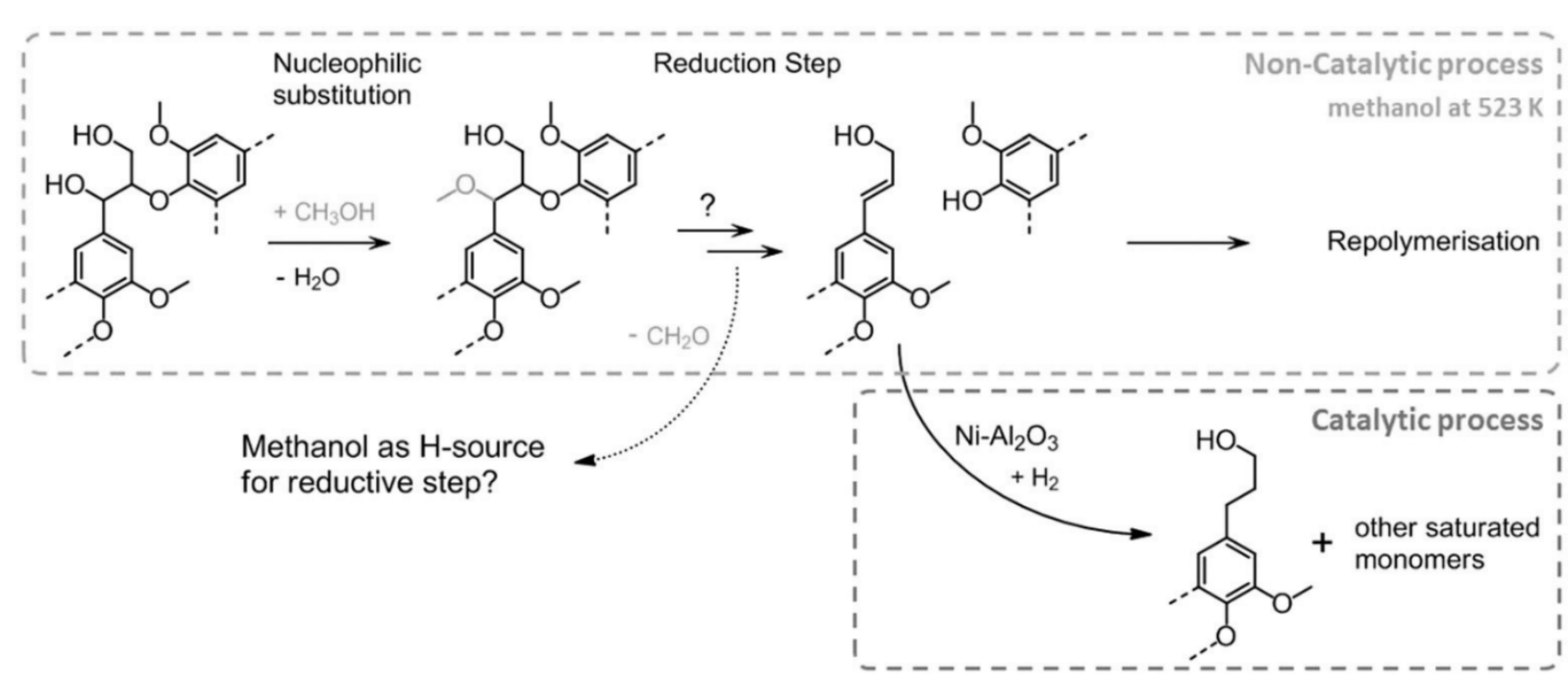

Scheme 1. Suggested reaction mechanism of solvolytic $\beta-\mathrm{O}-4$ bond breaking in the presence of methanol over an $\alpha$-methoxylated $\beta$-O-4 intermediate [28] - Reproduced by permission of The Royal Society of Chemistry.

of $\mathrm{Ni} / \mathrm{Al}_{2} \mathrm{O}_{3}$ promotes hydrogenation and facilitates stabilisation of unsaturated intermediates and further suppresses fast repolymerisation of the intermediates. Nevertheless, catalyst deactivation occurred [28] and it could be regenerated by thermal $\mathrm{H}_{2}$ treatment. The use of Raney nickel catalyst in liquefaction of green waste (straw: wood: grass mixture) in tetraline solvent medium at $320{ }^{\circ} \mathrm{C}$ enhanced the gas yield because of the dehydration of solvent and it resulted in the hydrogenation of the oil and improved quality [31]. In addition, Ferrini et al. [34] confirmed that Raney Ni catalyst was active upon fractionation of wood in 2-Propanol: water $(7: 3 \mathrm{v} / \mathrm{v})$ solvent medium [34, 36]. According to these reports [34, 36], the role of the catalytic material was to transfer lignin fragments released by solvolysis into low molecular weight monomers via depolymerisation through catalytic hydrogen transfer reactions. Furthermore, Ni and Fe have been supported on phenantroline/carbon and applied in wood fractionation. In accordance to these results [38], however, Co was shown to be more efficient than other catalysts (see below) [38]. When a bimetallic $\mathrm{Ni}-\mathrm{W}_{2} \mathrm{C} / \mathrm{AC}$ catalyst was used upon one-pot catalytic hydrocracking of lignocellulose (wood) material into chemicals [26], introduction of $\mathrm{W}_{2} \mathrm{C}$ also facilitated cellulose and hemicellulose fractionation in addition to lignin in water medium [26]. Transformation of cellulose and hemicellulose proceeded over this catalyst into valuable ethylene glycol and other diols and, in total $75.6 \%$ yield was obtained. At the same time, lignin was selectively converted into phenolic monomers with the yield of $46.5 \%$ [26].

The reductive catalytic fractionation of untreated birch wood occurred over cobalt on phenantroline/ carbon (Co-Phen/C) catalyst at $200{ }^{\circ} \mathrm{C}$ [38]. The cobalt catalyst stabilized the reactive intermediates generated through organosolv processing by hydrogen transfer and hydrogenolysis reactions and cleavage of $\beta-\mathrm{O}-4$ bonds was mediated by the hydrogenolysis reactions [38]. The direct liquefaction of wood biomass was also investigated over Co$\mathrm{Mo} / \gamma-\mathrm{Al}_{2} \mathrm{O}_{3}$ and $\mathrm{Pt} / \gamma-\mathrm{Al}_{2} \mathrm{O}_{3}$ in tetraline at $400{ }^{\circ} \mathrm{C}$. Co-Mo and Pt-based catalysts promoted hydrotreating followed by the formation of lighter liquid and gaseous products [32]. In this work, it was also concluded that several other catalysts, i.e. $\mathrm{Pd} / \mathrm{C}$, $\mathrm{Cu} / \mathrm{ZnO} / \mathrm{Al}_{2} \mathrm{O}_{3}, \mathrm{Cu} / \mathrm{CeO}_{2}, \quad \mathrm{Mo}_{2} \mathrm{C} / \mathrm{AC}$ promoted hydrogenation under similar liquefaction conditions under inert atmosphere [35].

Wood liquefaction have been demonstrated both over homogeneous and heterogeneous iron catalysts $[29,30]$. In case of a homogeneous $\mathrm{FeSO}_{4}$ catalyst, under sub- and super-critical ethanol medium with 50 bar hydrogen initial pressure [29], biomass fractionation occurred resulting in 
$88 \%$ conversion of wood (Table 1, entry 7). The results show that Fe-based catalyst enhanced the formation of bio-oil and the amount of gaseous products was relatively low. In addition, water and char were formed during liquefaction process under sub- and super-critical ethanol [29]. Hydrogen gas at high temperatures suppressed condensation reactions via stabilization of the formed free radicals. Supercritical primary and secondary alcohols also act as hydrogen donors during wood liquefaction [29]. Liquefaction of birch wood over Fe-H-Beta-150 catalyst (150 denoted $\mathrm{SiO}_{2} / \mathrm{Al}_{2} \mathrm{O}_{3}$ ratio) was reported by Jogi et al. [30] who used 5 bar of initial hydrogen pressure in super-critical ethanol. The results revealed that hemicellulose and lignin degradation increased over strongly Brønsted acidic Fe-HBeta-150 catalyst even under very low initial hydrogen pressures [30].

Several noble metal catalysts including Pd [27], $\mathrm{Ru}$ [27], and Pt [35] have been used in hydrothermal liquefaction of wood. For example, catalytic fractionation of birch wood was performed over commercial $\mathrm{Ru} / \mathrm{C}$ or $\mathrm{Pd} / \mathrm{C}$ catalysts in the presence of methanol as a solvent [27]. The yield of phenolic monomers, di- and oligomers over these catalysts was reported to reach $50 \%$ (Table 1, entry 9). When the catalytic material chosen was $\mathrm{Pd} / \mathrm{C}$ instead of $\mathrm{Ru} / \mathrm{C}$, enhanced yields of lignin derived phenolic monomers were obtained (Table 1, entry 9) [27]. Most of the lignin sub-components were linked together with $-\mathrm{CH}_{2} \mathrm{OH}$-substituted ethylene bonds. In the liquefaction process, breaking of $\mathrm{C}-\mathrm{H}$ bonds is metal dependent, i.e. higher amount of $-\mathrm{OH}-$ containing products were formed over Pd catalysts in comparison to $\mathrm{Ru}$ [27]. $\mathrm{Ru} / \mathrm{C}$ promoted formation of dimers with n-propyl end-chains, while $\mathrm{Pd} / \mathrm{C}$ formed structurally identical dimers containing n-propyl end-chains. It was also reported by Bosch et al. that hemicellulose retention was higher in the case of $\mathrm{Pd} / \mathrm{C}$ in comparison to $\mathrm{Ru} / \mathrm{C}$ [27]. The role of catalytic material in this approach was depolymerisation of lignin and formation of hydrogen via methanol reforming [35]. It was also reported in [35] that $\mathrm{Pt} / \gamma-\mathrm{Al}_{2} \mathrm{O}_{3}$ catalyst was efficient in breaking of $\alpha-\mathrm{O}-4, \beta-\mathrm{O}-4$ bonds as well as forming unsaturated coniferyl/sinapyl alcohol, oxidizing syringyl units under inert atmosphere $\left(\mathrm{N}_{2}\right)$. A bimetallic catalyst $\mathrm{Pd}-\mathrm{W}_{2} \mathrm{C} / \mathrm{AC}$ was also used in the case of birch degradation and it facilitated lignin hydrogenation of phenolic monomers to hydroxyl group products, while $\mathrm{Ni}-\mathrm{W}_{2} \mathrm{C} / \mathrm{AC}$ and other noble metal-doped catalytic materials favour the dehydroxylation reactions [26].

Selection of the catalyst support is also an important issue in wood fractionation [35]. The use of $\gamma-\mathrm{Al}_{2} \mathrm{O}_{3}$ as a support during hydrothermal liquefaction of wood is not favorable since it is not stable at elevated temperatures. Open literature shows that carbon is more stable than $\gamma-\mathrm{Al}_{2} \mathrm{O}_{3}$ support; for example, in the case of $\mathrm{Pt} / \mathrm{C}$ in comparison to $\mathrm{Pt} / \gamma-\mathrm{Al}_{2} \mathrm{O}_{3}$ under identical wood liquefaction conditions, the monomer yields obtained were $45 \%$ and $46 \%$, respectively [35] The results revealed that only $\mathrm{Pd} / \mathrm{C}$ demonstrated performance closest to the one over $\mathrm{Pt} / \gamma-\mathrm{Al}_{2} \mathrm{O}_{3}$. Obviously, carbon support can remain more stable under liquefaction conditions than $\gamma-\mathrm{Al}_{2} \mathrm{O}_{3}$ [35].

\section{Reaction conditions}

\subsection{Influence of temperature}

$\mathrm{Ni}$ typically requires higher temperatures upon wood liquefaction [34] in comparison to noble metal catalysts, such as $\mathrm{Pd} / \mathrm{C}$ [27] and $\mathrm{Ru} / \mathrm{C}$ [27]. When studying delignification of poplar wood over Raney Ni catalyst in 2-propanol: water (7/3 $\mathrm{v} / \mathrm{v}$ ) medium, the delignification degree of poplar increased from $53 \%$ to $87 \%$ when the temperature was increased from $160{ }^{\circ} \mathrm{C}$ to $220^{\circ} \mathrm{C}$ and, at the same time, the biocrude yield increased from $15 \%$ to $26 \%$ [34]. These results were supported by the gel chromatograms (Figure 1) [34]. In the case of Raney Ni at higher temperatures such as $320^{\circ} \mathrm{C}$, dehydrogenation and deoxygenation reactions were dominating and, importantly, the gas yield increased above $330{ }^{\circ} \mathrm{C}$ [31]. When $\mathrm{Pd} / \mathrm{C}$ was used in birch fractionation with methanol as a solvent at $180{ }^{\circ} \mathrm{C}$, about 55 wt. \% mono-phenolic compounds were obtained, mainly alkylmethoxyphenols [45].

\subsection{Influence of gas atmosphere}

Throughout the liquefaction process, hydrogen plays a vital role. Hydrogen enhanced the depolymerisation of lignin into lignin fragments 


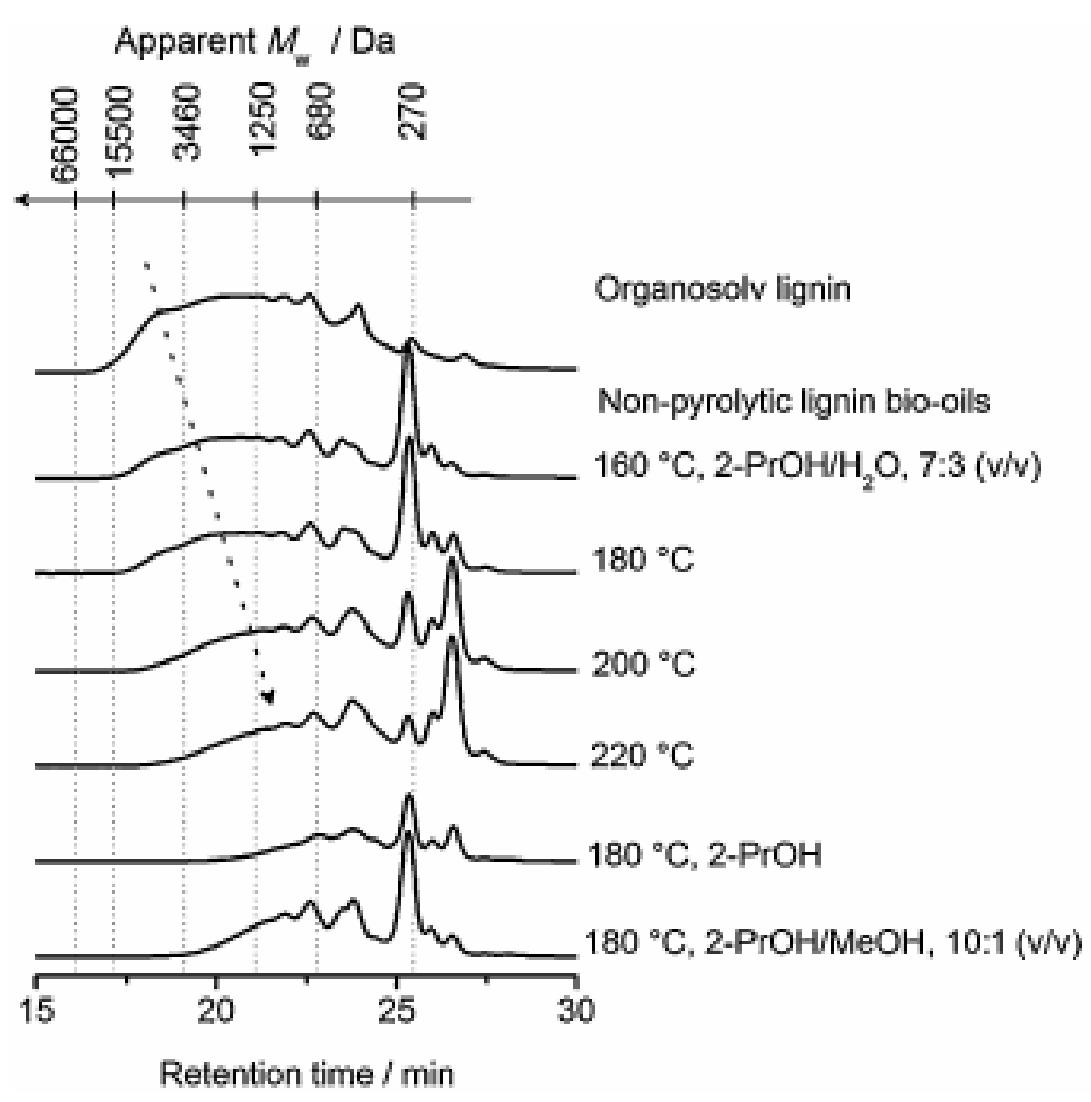

Figure 1. Gel permeation chromatograms of organosolv lignin and lignin bio-oils obtained at various reaction condition over Raney Ni-catalysts [34] (Reprinted from Ferrini, P. and Rinaldi, R. 2014, Angew. Chem. Int. Ed., 53, 8634 with permission from John Wiley and Sons).

and stabilized the lignin monomer intermediates. To determine the contribution of hydrogen solubility, different hydrogen pressures were used upon birch fractionation [28]. The results revealed that high hydrogen pressures promote high phenolic monomer yields and selectivity towards 4-n-propanolsyringol, 4-n-propylsyringol over $\mathrm{Ni} / \mathrm{Al}_{2} \mathrm{O}_{3}$ catalyst [28]. As a conclusion from these results, it can be seen that under five bar hydrogen, the monomer yield was only $27 \%$ after $3 \mathrm{~h}$ with relative selectivity towards unsaturated monomers being about $26 \%$. On the other hand, under 50 bar hydrogen, the monomer yield was $37 \%$ and a low selectivity (8\%) towards unsaturated monomers was obtained [28]. When increasing the hydrogen pressure from 5 bar to 50 bar, the yield of 4-npropanolsyringol increased (29 to $70 \%$ ) while the yield of 4-n-propyl decreased (22 to 7\%) [28]. The results clearly showed that hydrogenolysis reactions has a negative order with respect to hydrogen pressure and, at the same time, conversion of 4-n-propanolsyringol to 4-n-propylsyringol decreased when hydrogen pressure increased [28]. In addition, a higher initial hydrogen pressure also increased the yield of bio-oil [29].

\subsection{Influence of solvent}

A solvent can act as a hydrogen donor upon wood fractionation. Such solvents are e.g. propanol [34], formic acid [38] and tetraline [31]. A catalytic fractionation of wood biomass over Raney $\mathrm{Ni}$ in the presence of 2-propanol: water medium $(7: 3 \mathrm{v} / \mathrm{v})$ was demonstrated by Ferrini et al. [34]. In their work it was demonstrated that wood biomass degradation occurred over a reducing agent, 2-propanol, which generated hydrogen radicals and promoted lignin fractionation. Hydrogen transfer process generated also acetone from 2-propanol. The advantage of this process is that it does not require a large reactor to manage 
high hydrogen pressure [34]. Hemicellulose deacetylation occurred during wood fraction over Raney nickel catalyst reducing the $\mathrm{pH}$ value of bio oil from $\mathrm{pH} 7$ to $\mathrm{pH} 4.7$ and, simultaneously, resulted in effective bond breaking of $\alpha-\mathrm{O}-4$ in lignin, while $\beta-\mathrm{O}-4$ bond breaking did not occur [34]. It was concluded in [34] that Raney $\mathrm{Ni}$ together with 2-propanol as a solvent is capable to hydrogenate phenols, aldehydes, ketones as well diaryl and aryl alkyl ethers. Furthermore, Ouyang et al. reported that wood liquefaction occurred under a solvent consisting of methanol and water which causes generation of hydrogen radicals under otherwise inert nitrogen atmosphere over $\mathrm{Pt} / \gamma-\mathrm{Al}_{2} \mathrm{O}_{3}$ catalyst [35].

Two different hydrogen donor solvents $(\mathrm{HCOOH}$ and HCOONa) in ethanol: water $(1: 1 \mathrm{v} / \mathrm{v})$ medium were applied in wood fractionation over Co on phenanthroline/carbon catalyst (Co-phen/C) by Rautiainen et al. [38], who reported that the yield of lignin-derived mono-phenolic compounds was 34 wt.\% [38]. Interestingly, even HCOONa without formic acid resulted in formation of relatively high amounts of phenolic monomers [38]. The role of Co-Phen/C catalyst was presumably to complete the reductive breaking of lignin fragments and to stabilize the reactive monomers [38]. The results of [34] were also supported by the gel permeation chromatography (GPC) as shown in Figure 2, in which high amount of phenolic monomers were obtained in the presence of cobalt catalyst only. This result is in a good agreement with the one reported in Bosch et al. [28], who used $\mathrm{Ni} / \mathrm{Al}_{2} \mathrm{O}_{3}$ upon wood fractionation.

Different bio-based solvents have been used to determine the limitations of fractionation processes over polarity bases (Table 2) [33]. To determine the delignification efficiency of wood, we need to consider different parameters, such as polarity, Lewis acidity and Lewis basicity. Catalytic wood fractionation over $\mathrm{Pd} / \mathrm{C}$ in the presence of methanol or ethylene glycol efficiently occurs fast due to high solvent polarity, Lewis acidity and basicity (Figure 3) [33]. In addition, the amount of hydroxyl groups in dimeric compounds was lower in the case of ethylene glycol than in the case of methanol [33]. Birch fractionation occurred also rapidly over $\mathrm{Pt} / \mathrm{Al}_{2} \mathrm{O}_{3}$ in methanol-water mixture in inert atmosphere (Table 2, entry 3) indicating the importance of methanol delivering hydrogen into the reaction system [35].

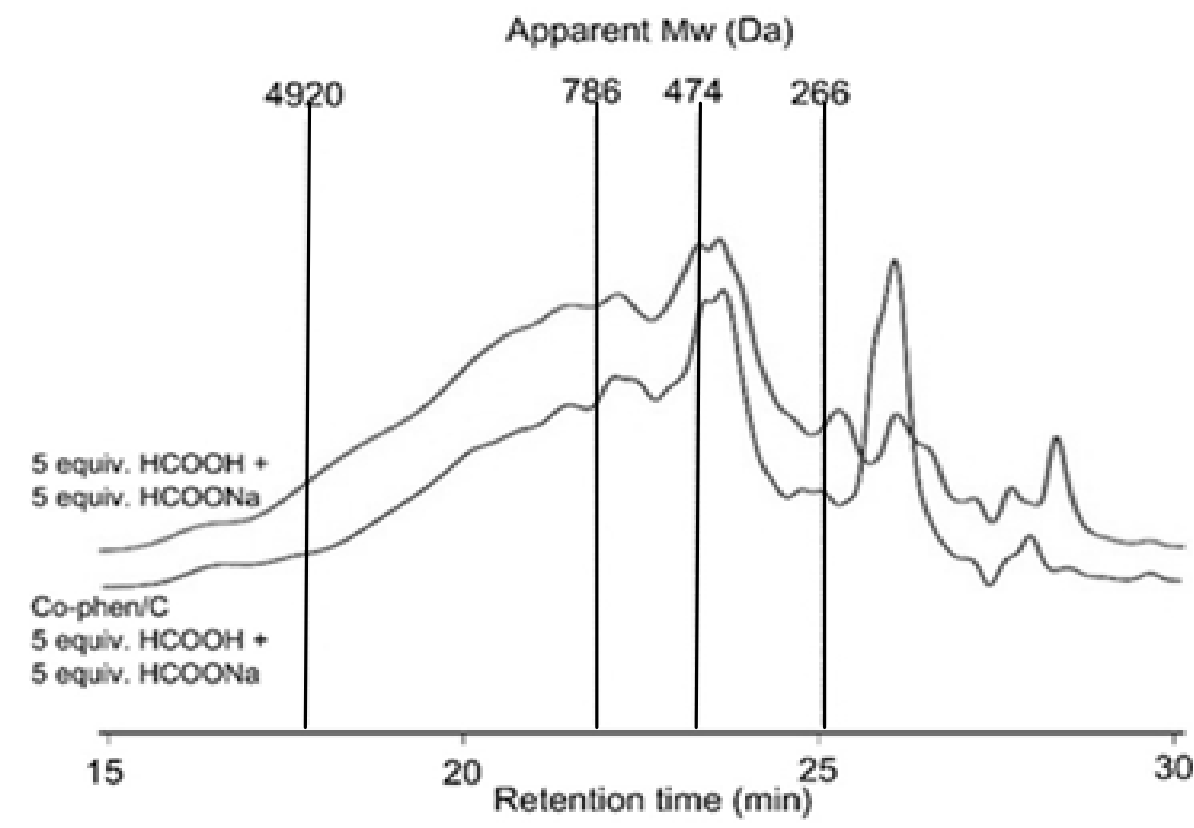

Figure 2. GPC chromatograms obtained from fractionation of birch to lignin oil at $200{ }^{\circ} \mathrm{C}$ in a 4 h run time under EtOH: $\mathrm{H}_{2} \mathrm{O}$ (1:1 v/v) (Redrawn from [38]). 
Table 2. Liquefaction of wood biomass over heterogeneous catalysts with different solvents and gas atmospheres.

\begin{tabular}{|c|c|c|c|c|c|c|}
\hline Entry & $\begin{array}{c}\text { Feedstock } \\
\text { (size) }\end{array}$ & $\begin{array}{c}\text { Solvent } \\
\text { medium }\end{array}$ & $\begin{array}{c}\text { Catalytic } \\
\text { material }\end{array}$ & $\begin{array}{c}\text { Liquefaction } \\
\text { conditions }\end{array}$ & $\begin{array}{c}\text { Yield } \\
\text { (wt. \%) }\end{array}$ & Ref. \\
\hline 1 & $\begin{array}{c}\text { Birch } \\
(250-500 \mu \mathrm{m})\end{array}$ & $\begin{array}{c}\text { Methanol and } \\
\text { ethylene glycol }\end{array}$ & $\mathrm{Pd} / \mathrm{C}$ & $\begin{array}{c}200^{\circ} \mathrm{C}, 3 \mathrm{~h}, \\
30 \mathrm{bar} \mathrm{H}_{2}, 700 \mathrm{rpm}\end{array}$ & $55^{\mathrm{a}}$ and $50^{\mathrm{a}}$ & {$[33]$} \\
\hline 2 & $\begin{array}{c}\text { Poplar } \\
(2 \mathrm{~mm})\end{array}$ & $\begin{array}{c}\text { 2-proponal: water } \\
(7: 3 \mathrm{v} / \mathrm{v})\end{array}$ & Raney Ni & $\begin{array}{c}180^{\circ} \mathrm{C}, 3 \mathrm{~h}, \\
\text { no external } \mathrm{H}_{2}\end{array}$ & $8^{\mathrm{b}}, 26^{\mathrm{c}}$ & {$[34]$} \\
\hline 3 & $\begin{array}{c}\text { Birch } \\
(125-300 \mu \mathrm{m})\end{array}$ & $\begin{array}{c}\text { Methanol: water } \\
(1: 2 \mathrm{~mol} / \mathrm{mol})\end{array}$ & $\mathrm{Pt} / \gamma-\mathrm{Al}_{2} \mathrm{O}_{3}$ & $\begin{array}{c}230^{\circ} \mathrm{C}, 3 \mathrm{~h}, \\
30 \mathrm{bar} \mathrm{N}_{2}, 500 \mathrm{rpm}\end{array}$ & $46^{\mathrm{a}}$ & {$[35]$} \\
\hline 4 & $\begin{array}{c}\text { Poplar or } \\
\text { spruce }\end{array}$ & $\begin{array}{c}2-\text { proponal: water } \\
(7: 3 \mathrm{v} / \mathrm{v})\end{array}$ & Raney $\mathrm{Ni}$ & $\begin{array}{c}180^{\circ} \mathrm{C}, 3 \mathrm{~h}, \\
\text { no external } \mathrm{H}_{2}\end{array}$ & $50^{\mathrm{a}}$ & {$[36]$} \\
\hline
\end{tabular}

${ }^{\mathrm{a}}$ :phenolic monomer, ${ }^{\mathrm{b}}$ :delignification, ${ }^{\mathrm{c}}$ :bio-oil yield.

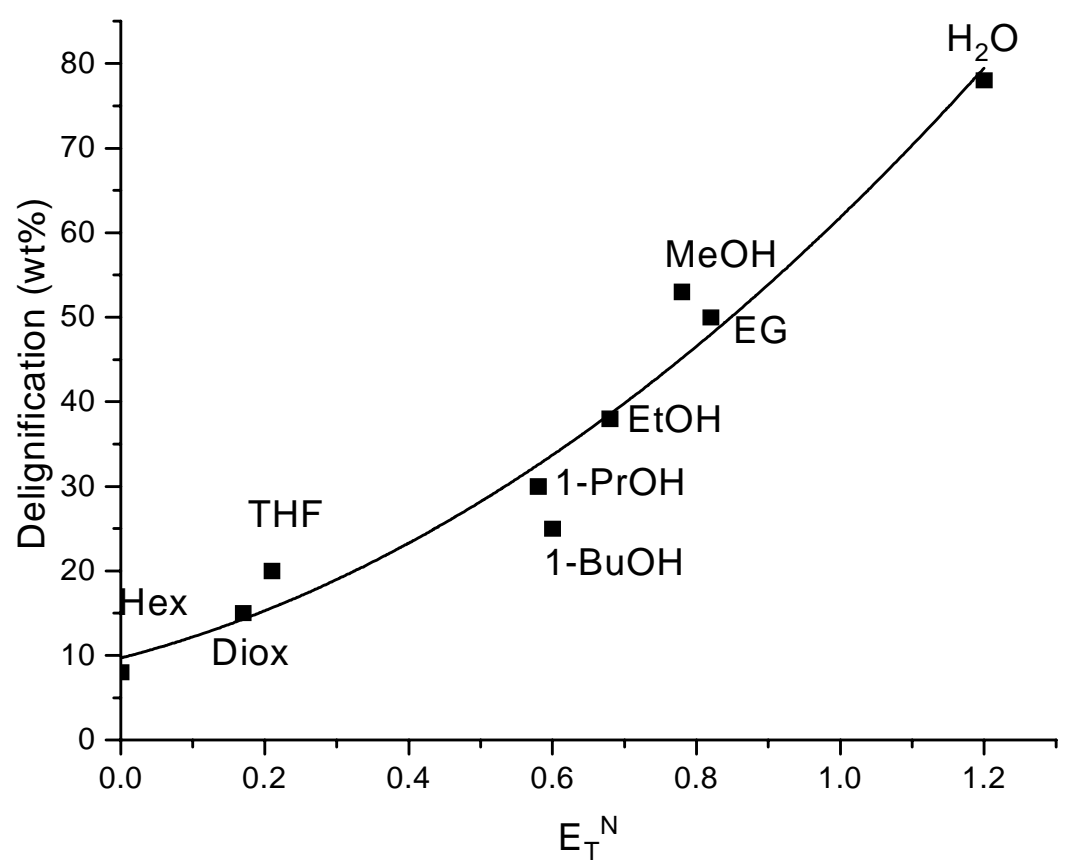

Figure 3. Delignification of birch vs solvent polarity (Redrawn from [33]).

\subsection{Influence of co-solvents or co-catalysts}

Co-catalyst and co-solvents can also have a major influence in terms of wood fractionation efficiency. When wood biomass is subjected to acidic or basic conditions, co-catalyst are required. The nature of solvent determines the extent to which hydrolysis of hemicellulose along with delignification of lignin occurs. Different research groups have worked on the application of co-solvents. For example, wood liquefaction in methanol over
$\mathrm{Pd} / \mathrm{C}$ catalyst with an addition of phosphoric acid $\left(\mathrm{H}_{3} \mathrm{PO}_{4}\right)$ or sodium hydroxide $(\mathrm{NaOH})$ as a cocatalyst, under 20 bar initial hydrogen atmosphere was investigated by Renders et al. (Table 3, entry 1) [37]. An addition of a small amount of acid into the reaction system leads both to delignification and alcoholysis of hemicellulose while leaving the cellulose intact [37]. The increased concentration of acid gave enhanced monomer yield until the theoretical maximum was reached. The best monomer yield of the lignin product oil was 44 wt.\%, 
Table 3. Liquefaction of wood biomass over heterogeneous catalysts along with co-catalyst and different solvent media.

\begin{tabular}{|c|c|c|c|c|c|c|}
\hline Entry & $\begin{array}{l}\text { Feedstock } \\
\quad \text { (size) }\end{array}$ & $\begin{array}{l}\text { Solvent } \\
\text { medium }\end{array}$ & $\begin{array}{l}\text { Catalytic } \\
\text { material }\end{array}$ & $\begin{array}{c}\text { Liquefaction } \\
\text { conditions }\end{array}$ & $\begin{array}{l}\text { Yield } \\
\text { (wt. \%) }\end{array}$ & Ref. \\
\hline 1 & $\begin{array}{c}\text { Poplar } \\
(250-500 \mu \mathrm{m})\end{array}$ & Methanol & $\begin{array}{c}\mathrm{Pd} / \mathrm{C}, \\
\mathrm{H}_{3} \mathrm{PO}_{4} \text { or } \mathrm{NaOH} \\
\text { (co-solvent) }\end{array}$ & $\begin{array}{l}200^{\circ} \mathrm{C}, 3 \mathrm{~h}, \\
20 \text { bar } \mathrm{H}_{2}, \\
750 \mathrm{rpm},\end{array}$ & $96^{\mathrm{C}}$ or $85^{\mathrm{c}}$ & [37] \\
\hline 2 & $\begin{array}{c}\text { Birch } \\
(\leq 250 \mu \mathrm{m})\end{array}$ & $\begin{array}{l}\text { Ethanol: } \\
\text { water } \\
(5: 5 \mathrm{v} / \mathrm{v})\end{array}$ & $\begin{array}{c}\text { Co-Phenanthroline/C, } \\
\text { HCOOH } \\
\text { (co-solvent) }\end{array}$ & $\begin{array}{l}200^{\circ} \mathrm{C}, 4 \mathrm{~h} \text {, } \\
\text { no external } \mathrm{H}_{2}\end{array}$ & $34^{\mathrm{a}}$ & [38] \\
\hline 3 & $\begin{array}{c}\text { Pine } \\
(170-420 \mu \mathrm{m})\end{array}$ & $\begin{array}{l}\text { Aqueous } \\
\text { Phosphoric } \\
\text { acid }\end{array}$ & $\begin{array}{c}\mathrm{LiTaMoO}_{6} \text { layered over } \\
\mathrm{Ru} / \mathrm{C}\end{array}$ & $\begin{array}{l}230^{\circ} \mathrm{C}, 24 \mathrm{~h}, \\
60 \mathrm{bar} \mathrm{\textrm {H } _ { 2 }} \\
450 \mathrm{rpm}\end{array}$ & $28^{\mathrm{a}}, 63^{\mathrm{b}}$ & [39] \\
\hline 4 & $\begin{array}{c}\text { Birch } \\
(125-300 \mu \mathrm{m})\end{array}$ & Methanol & $\begin{array}{l}\mathrm{Pd} / \mathrm{C} \text { combined } \mathrm{Yb} \\
(\mathrm{OTf})_{3}\end{array}$ & $\begin{array}{c}200^{\circ} \mathrm{C}, \\
20 \text { bar } \mathrm{H}_{2}, 2 \mathrm{~h}, \\
700 \mathrm{rpm}\end{array}$ & $55^{\mathrm{a}}$ & [45] \\
\hline
\end{tabular}

${ }^{\mathrm{a}}$ :phenolic monomer, ${ }^{\mathrm{b}}$ :alkanes, ${ }^{\mathrm{c}}$ :delignification efficiency.

composed mainly of n-propanol substituent (83 wt. \%). The high selectivity of monomer indicates efficient lignin depolymerisation [37]. However, under alkaline conditions, the catalytic activity decreased, although lignin depolymerization was inhibited via repolymerisation. In case of monomer distribution in alkaline medium, lesser amounts of n-propanol-substituted phenolic monomers were formed and, simultaneously, the amounts of ethylguaiacol and syringol were ca. 28 wt. \% of the total composition of monomers [37]. $\mathrm{Ru} / \mathrm{C}$ and $\mathrm{Ni} / \mathrm{SiO}_{2}$ catalysts were also applied under alkaline conditions even though the response indicates low depolymerisation activity and low monomer yields. Different bioderived solvents such as ethanol, 1-butanol, and ethylene glycol were also applied. Nevertheless, the degree of depolymerisation efficiency and monomer yields were not improved under alkaline conditions. It can be stated that repolymerisation activity is combined with the use of base and is not linked to the applied catalyst [37]. The mass balance closure of solid pulp after applying the catalytic liquefaction condition over acidic or basic conditions can be seen in Figure 4. Under acidic conditions, hemicellulose components such as the combination of xylose, arabinose, mannose and galactose were absent in the solid pulp or solubilized and found in the liquid reaction mixture [37].
Liquefaction of lignocellulosic biomass over $\mathrm{Ru} / \mathrm{C}$ catalyst under aqueous acidic conditions was demonstrated by Liu et al. [39] producing gasolinerange alkane in the presence of phosphoric acid $\left(\mathrm{H}_{3} \mathrm{PO}_{4}\right) . \mathrm{Ru} / \mathrm{C}$ is an efficient hydrogenation and hydrogenolysis catalyst; however, when applied in the transformation of cellulose in aqueous $\mathrm{H}_{3} \mathrm{PO}_{4}$, isosorbide was obtained as a byproduct besides low concentration of alkanes [39]. The formation of isosorbide was, however, suppressed upon liquefaction of untreated pine sawdust using a layered $\mathrm{LiTaMoO}_{6}$ co-catalyst, together with $\mathrm{Ru} / \mathrm{C}$ in aqueous $\mathrm{H}_{3} \mathrm{PO}_{4}$ medium during $24 \mathrm{~h}$ under 60 bar initial hydrogen pressure. The reaction was giving 62.8 wt. \% and 16.9 wt. \% alkanes $C_{5}$ and $\mathrm{C}_{6}$, respectively, due to fractionation of hemicellulose and cellulose [39]. This catalytic system facilitated breaking of $\beta-\mathrm{O}-4$ and $4-\mathrm{O}-5$ bonds, which gives rise to lignin degradation products such as 4-alkyl-2-methoxy phenol and p-alkyl phenol [39]. The above-mentioned results indicate that the addition of a homogeneous cocatalyst enhances lignin depolymerisation into monomers. On the other hand, the use of aqueous acids upon liquefaction of wood biomass e.g. $\mathrm{HCl}$, $\mathrm{H}_{2} \mathrm{SO}_{4}$, and $\mathrm{H}_{3} \mathrm{PO}_{4}$ enhanced the delignification (Table 3, entry 3) [39], although hydrolysis of sugar into furfural and 5-hydroxymethyl furfural occurred simultaneously. In addition, these products 


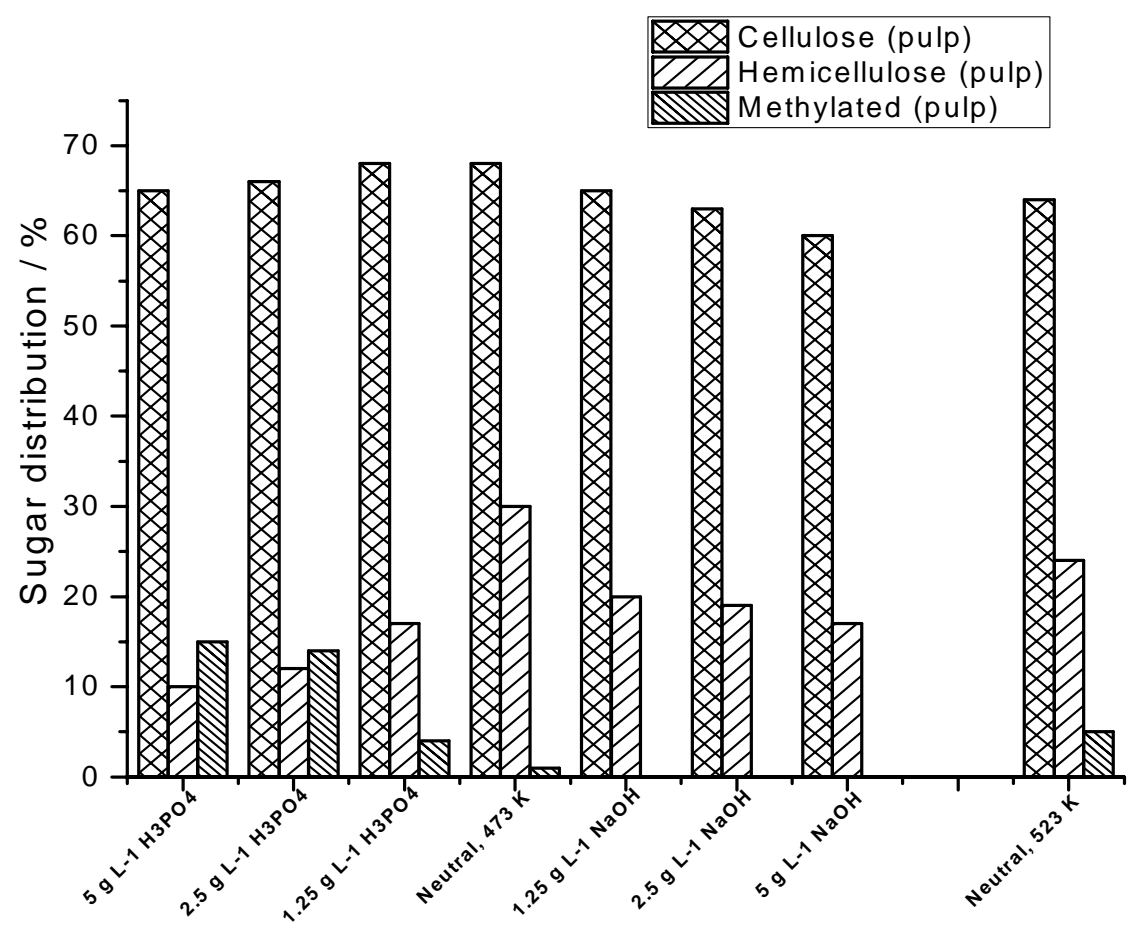

Figure 4. Mass balance of carbohydrate components of poplar wood after liquefaction under acidic and basic conditions over Pd/C (Redrawn from [37]).

can promote condensation of lignin fragments and acid catalysts can cause corrosion [40, 41]. To overcome the above-mentioned challenges, Lewis $\left(\mathrm{Zn}^{3+}, \mathrm{Al}^{3+}\right)$ and Brønsted acids have been applied. These catalysts enhance the fractionation of lignin itself [42, 43]. For example, metal triflates $\left(\mathrm{M}(\mathrm{OTf})_{\mathrm{n}}\right)$ were used together with $\mathrm{Pd} / \mathrm{C}$ catalyst under 20 bar $\mathrm{H}_{2}$ initial pressure in methanol as a solvent in wood liquefaction [44]. These Lewis acid catalysts are water tolerant, non-corrosive, thermally stable and active for breaking bonds between lignin and carbohydrates. Metal triflates and $\mathrm{Pd} / \mathrm{C}$ together promote tandem extraction of lignin and depolymerisation of lignin fragments unlike the traditional Lewis acid catalysts such as $\mathrm{AlCl}_{3}, \mathrm{BF}_{3}, \mathrm{TiCl}_{4}$ and $\mathrm{SnCl}_{4}$ [44]. Furthermore, $\mathrm{Yb}$ (III) triflates were applied as a co-catalyst along with $\mathrm{Pd} / \mathrm{C}$ catalyst upon liquefaction of wood biomass as demonstrated in [44]. $\mathrm{Pd} / \mathrm{C}$ promoted deconstruction of ether bonds, while $\mathrm{Yb}$ (III) enhanced cleavage of $\beta-\mathrm{O}-4$ bonds and generated monomeric lignin fragments [44]. The yield of lignin monomers including 4-n-propylsyringol, 4-n-propanolsyringol, and 3-(4-hydroxy-3methoxyphenyl)-1-propanol (4-n-propanolguaiacol,
PG-OH) over $\mathrm{Pd} / \mathrm{C}$ and $\mathrm{Yb}$ (III) was 43 wt. \%. In addition, other metal triflates including $\mathrm{Ni}, \mathrm{Cu}$, $\mathrm{Al}, \mathrm{Sc}, \mathrm{La}$ and $\mathrm{Hf}$ were also tested under similar liquefaction conditions over $\mathrm{Pd} / \mathrm{C}$ catalyst [44]. From these strong Lewis acids, $\mathrm{Al}$ (III) and Hf (IV) gave high amounts of methyl lated C5 sugars due to their high charge and they also facilitated efficient removal of hemicellulose (Table 3, entry 4) $[44,45]$. Different types of biomass were used to produce lignin monomers over $\mathrm{Pd} / \mathrm{C}$ and $\mathrm{Pd} / \mathrm{C}+$ $\mathrm{Yb}$ (III)-triflate in methanol at $200{ }^{\circ} \mathrm{C}$ to determine the effect of the $\mathrm{Yb}$ triflate. The addition of $\mathrm{Yb}$ triflates to $\mathrm{Pd} / \mathrm{C}$ resulted in an enhanced yield of lignin monomers over hard and softwood (Figure 5a) [44], although not in the soda lignin and wheat chaff. In soda lignin, only a partial degradation through $\mathrm{C}-\mathrm{O}-\mathrm{C}$ interlinkages occurred due to the presence of reactive lignin, which further recombined to form new C-C bonds [44]. On the other hand, wheat chaff lignin has a high amount of $\mathrm{H}$-units and its liquefaction resulted in less breaking of C-O-C interlinkage units and formation of high amounts of less reactive C-C linkages [44]. The highest lignin monomer yields were obtained from oak and birch (Figure 5b). 

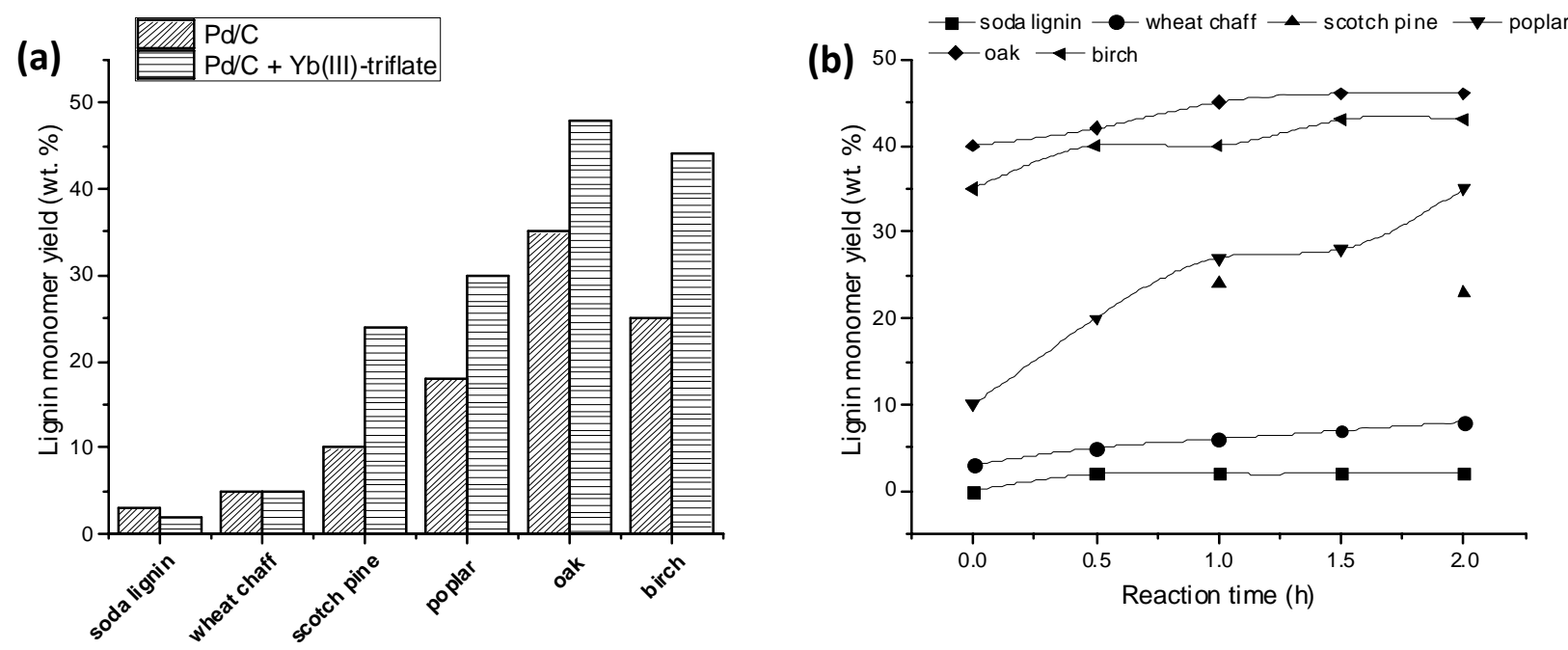

Figure 5. a) Lignin monomer yield of different biomass treated at $200{ }^{\circ} \mathrm{C}$ in methanol for $1 \mathrm{~h}$ reaction time, b) kinetics for formation of lignin monomers over $\mathrm{Pd} / \mathrm{C}+\mathrm{Yb}(\mathrm{III})+$ triflate under the same conditions. Notation: Initial lignin content of extracted wood (acid insoluble + acid soluble fractions) was as follows: wheat chaff 20.5 wt. \%, scotch pine 28.8 wt. \%, poplar 24.8 wt. \%, oak 27.5 wt. \% and birch 23.8 wt. \% (Redrawn from [44]).

\subsection{Influence of feedstock}

The type of feedstock, i.e. softwood or hardwood has a major impact on the fractionation efficiency [44]. Fractionation of pine, poplar, oak and birch were investigated over $\mathrm{Pd} / \mathrm{C}$ in combination with ytterbium (Yb(III) triflate, at $200{ }^{\circ} \mathrm{C}$ in methanol [45]. The results revealed that after $1 \mathrm{~h}$ ca. $23 \mathrm{wt}$ \% lignin monomers were obtained from Scotch pine, while more than $40 \%$ lignin monomer yields were achieved in the case of oak and birch. The reason for the lower fractionation efficiency for pine is its lignin structure, which contains more syringyl groups [47], which are more difficult to be cleaved. Analogously to the results of Huang et al. [44], lower fractionation efficiency for pine was observed over $\mathrm{Pd} / \mathrm{C}$ in the presence of phosphoric acid in methanol at $200{ }^{\circ} \mathrm{C}$ in comparison to poplar in ref. [37].

\section{Scale-up studies}

Scale-up studies have been very scarcely performed upon wood liquefaction [46]. Scale up is an important step during development of the reductive wood fractionation towards industrial utilization. It was reported by Huang et al. that large oak particles and relatively high initial loading of wood particles were used upon reductive wood fractionation, i.e. $100 \mathrm{~g}$ dry oak particles of the size between $300-1000 \mu \mathrm{m}$ were fractionated in 2 liters of methanol using $\mathrm{Pd} / \mathrm{C}-\mathrm{Al}$-triflate catalyst system at $180{ }^{\circ} \mathrm{C}$ [45]. The results revealed that 46 wt. \% monomeric phenolic compounds were obtained in $4 \mathrm{~h}$. In addition, only a slightly lower lignin monomer yield of 40 wt. \% was obtained in the case of $0-300 \mu \mathrm{m}$ oak particles, showing that relatively high wood loading and large particle sizes could be used without prominently decreasing the yield of monomeric phenolic compounds [45].

\section{Catalyst recycling and regeneration}

Recycling of heterogeneous catalyst which is typically found as a mixture with the solid wood residue can be challenging. However, several methods such as utilization of magnetic particles [34], locating large catalyst pellets in a basket [38] or using specific solvent mixtures with $\mathrm{Pd} / \mathrm{C}$ catalyst [46] facilitated successful catalyst separation and reuse. A biphasic THF/sea water solvent system was used to separate $\mathrm{Pd} / \mathrm{C}$ catalyst from the solid wood residue after birch fractionation at $200{ }^{\circ} \mathrm{C}$ under 20 bar hydrogen in methanol when Yb-triflate was used as a co-catalyst by Guo et al. [46]. In their work, it was also possible to recirculate Yb-triflate catalyst from the reaction mixture after removal of the solid phase from the reaction mixture [46]. The results revealed that 
Yb-triflate could be used second time upon wood fraction with $\mathrm{Pd} / \mathrm{C}$ and wood. The yield of lignin monomers, however, decreased in the second and third experiment, most probably due to Pd sintering and leaching confirmed by inductively coupled plasma emission mass spectrometry (ICPMS) analysis. The authors stated that further studies are required [46]. Furthermore, reuse of $\mathrm{LiTaMoO}_{6}$ and $\mathrm{Ru} / \mathrm{C}$ was reported upon pine fractionation at $230{ }^{\circ} \mathrm{C}$ under 60 bar hydrogen in aqueous phosphoric acid by Liu et al. [39]. These catalysts were separated from solid wood residue by filtration, washed at $100{ }^{\circ} \mathrm{C}$ and dried prior to the next experiment. It should be pointed out here that fresh phosphoric acid was added. The yield of phenols after the first experiment was 16 wt. \% and it slightly decreased during the second and third experiment. The applied Raney Ni catalyst from the liquefaction system of poplar wood in 2-propanol:water medium was removed with a magnet and reused eight times after reconditioning of the catalyst at $200{ }^{\circ} \mathrm{C}$ in 2-propanol under autogenous pressure for four hours [34]. Regeneration and reuse of $\mathrm{Ni} / \mathrm{Al}_{2} \mathrm{O}_{3}$ pellets (with the size of $1.2 * 3 \mathrm{~mm}$ trilobe) which were in a basket was demonstrated in [28], in which birch fractionation was investigated in methanol. The reductive treatment of the spent $\mathrm{Ni}$ catalyst with hydrogen for $4 \mathrm{~h}$ at $500{ }^{\circ} \mathrm{C}$ was also demonstrated, resulting in an unaltered $\mathrm{Ni}(1.2 * 3 \mathrm{~mm}$ trilobe) catalyst [28].

\section{Concluding remarks and future perspectives}

Several process considerations have been recently investigated in wood liquefaction including specific separation steps and consecutive hydrodeoxygenation steps for lignin oil and catalytic transformation of sugars to hydroxymethylfurfural [46], liquefaction conditions producing alternatively either kraft pulp like cellulose fraction [44] or relatively pure cellulose suitable for production of bioethanol via fermentation [37, 28]. In addition, production of gasoline and jet fuels could be achieved via using $\mathrm{Ru} / \mathrm{C}$ together with $\mathrm{LiTaMoO}_{6}$ and phosphoric acid catalysts [39].

Both lignin oil and pulp can also be produced via wood fractionation over $\mathrm{Ni} / \mathrm{Al}_{2} \mathrm{O}_{3}$ pellets at $250{ }^{\circ} \mathrm{C}$ under 30 bar hydrogen in methanol followed by hydrodeoxygenation of lignin oil and pulp fermentation to bio-ethanol [28]. After bio-oil separation, the relatively pure cellulose fraction was saccharified with an enzyme mixture to sugars and semi-simultaneously fermented to ethanol using yeast. The ethanol yield was $73 \%$ of the maximum yield. Hydrodeoxygenation of birch-derived lignin oil to jet fuel compounds, including alkyl benzenes and cycloalkanes was demonstrated as a second step after birch liquefaction with Pd/C-Yb-triflate catalyst [46]. Separation of lignin oil from sugar fraction is easy via applying e.g. ethyl acetate-water mixture. During extraction, water soluble sugars are separated from lignin oil which remains in the organic phase. Lignin oil is purified via evaporation of an organic solvent. Hydrodeoxygenation of lignin oil could be facilitated using a bifunctional $\mathrm{Ru} / \mathrm{Nb}_{2} \mathrm{O}_{5}$ catalyst at $250^{\circ} \mathrm{C}$ in isopropanol-water-cyclohexane solvent mixture, thus facilitating transfer hydrogenation and hydrodeoxygenation. The main products were aromatic hydrocarbons together with a small amount of cycloalkanes.

Huang et al. [44] demonstrated the "lignin first concept”, in which lignin oil together with kraft pulp-type cellulose fraction can be obtained. In their work, Pd/C together with Lewis acid metal triflates were used as catalysts for wood liquefaction. The produced kraft pulp-like pulp was further utilized for paper production. In their work, it was also emphasized that alkylmethoxyphenols in lignin oil are not only suitable for fuel production, but they can also be used as valuable compounds (such as dihydroeugenol (aroma)) in fragrance industry.

Solvent selection in wood liquefaction process can be crucial for determining e.g. cellulose quality as pointed out by Schutyser et al. [33]. Methanol has been a suitable bio-derived solvent for wood liquefaction as reported earlier and it can be produced via demethoxylation of lignin oil [33]. It was also pointed out that recuperation of methanol is easy. On the other hand, bio-derived ethylene glycol facilitated production of easily accessible cellulose fibers during wood liquefaction at $200{ }^{\circ} \mathrm{C}$ over $\mathrm{Pd} / \mathrm{C}$ catalyst [33]. Such cellulose fibers can be further used for production of cellulose acetate or paper.

One-pot catalytic transformation of lignocellulosic biomass over $\mathrm{Ru} / \mathrm{C}$ - $\mathrm{LiMoO}_{6}$-phosphoric acid in 
water was demonstrated by Liu et al. [39]. In their work, both gasoline products (alkanes) and phenolic compounds were obtained under 60 bar hydrogen at $230{ }^{\circ} \mathrm{C}$. Phenolic compounds should be further hydrodeoxygenated to jet fuel components. It was concluded in [39] that further improvements are required, since catalyst deactivation occurred due to tar formation.

The above-mentioned examples from wood liquefaction and further processing of different fractions show that these methods have several possibilities, but most probably need still more development. It can, however, be stated that several of these methods have potential to be further developed towards industrial scale.

\section{ACKNOWLEDGEMENTS}

The authors would like to acknowledge the funding from Fortum foundation Finland (Project no: 201900066). This work is part of the activities of the Johan Gadolin Process Chemistry Centre at Åbo Akademi University. In Sweden, the Bio4Energy programme, the Kempe Foundations and Wallenberg Wood Science Center are acknowledged. This work is also partially financed by the TANDEM FOREST VALUES grant TFV 2018-0031 under auspices of the Royal Swedish Academy of Agriculture and Forestry, KSLA.

\section{CONFLICT OF INTEREST STATEMENT}

None of authors has any conflicts of interest to declare.

\section{REFERENCES}

1. Klass, D. L. 1998, Biomass for Renewable Energy, Fuels and Chemicals; Academic Press: San Diego.

2. Huber, G. W., Iborra, S. and Corma, A. 2006, Chem. Rev., 106, 4044.

3. Lin, Y.-C. and Huber, G. W. 2009, Energy Environ. Sci., 2, 68.

4. Lynd, L. R., Larson, E., Greene, N., Laser, M., Sheehan, J., Dale, B. E., McLaughlin, S. and Wang, M. 2009, Biofuels, Bioprod. Biorefin., 3, 113.

5. Strimbeck, G. R., Schaberg, P. G., Fossdal, C. G., Schröder, W. P. and Kjellsen, T. D. 2015, Frontiers in Plant Science, 6, 884.
6. Breda, N., Huc, R., Granier, A. and Dreyer, E. 2006, Ann. For. Sci., 63, 625.

7. Forti, R. and Henrard, M. (Ed.), 2016, Agriculture, Forestry and Fishery Statistics, Eurostat.

8. Amidon, T. E. and Liu, S. 2009, Biotechnol. Adv., 27, 542.

9. Upton, B. M. and Kasko, A. M. 2016, Chem. Rev., 116, 2275.

10. Luska, K. L., Migowski, P. and Leitner, W. 2015, Green Chem., 17, 3195.

11. Serrano-Ruiz, J. C., Luque, R. and SepúlvedaEscribano, A. 2011, Chem. Soc. Rev., 40, 5266.

12. Julis, J. and Leitner, W. 2012, Angew. Chem., Int. Ed., 51, 8615.

13. Xia, Q.-N., Cuan, Q., Liu, X.-H., Gong, X.Q., Lu, G. Z. and Wang, Y.-Q. 2014, Angew. Chem. Int. Ed., 53, 9755.

14. Saxena, R. C., Adhikari, D. K. and Goyal, H. B. 2009, Renew. Sust. Energy Reviews, 13, 167.

15. Anwar, Z., Gulfraz, M. and Irshad, M. 2014, J. Radiation Research and Applied Sciences, 7, 163.

16. Canabarro, N., Soares, J. F., Anchieta, C. G., Kelling, C. S. and Mazutti, M. A. 2013, Sustainable Chemical Processes, 1, 22.

17. Sharma, S., Meena, R., Sharma, A. and Goyal, P. K. 2014, IOSR Journal of Mechanical and Civil Engineering, 11(2), 28.

18. FazliOthaman, M., Sabudin, S. and Batcha, M. F. M. 2016, Int. J. Eng. Technol., 8(6), 2494.

19. Kim, J-Y., Lee, H. W., Lee, S. M., Jae, J. and Park, Y-K. 2019, Biores. Technol., 279, 373.

20. Cao, L., Zhang, C., Chen, H., Tsang, D. C. W., Luo, G., Zhang, S. and Chen, J. 2017, Biores. Technol., 245, 1184.

21. Bridgwater, A. V. 2012, Biomass and Bioenergy, 38, 68.

22. Horne, P. A. and Williams, P. T. 1996, Fuel, 75, 1051.

23. Scott, D. S., Plskorz, J. and Radleln, D. 1985, Ind. Eng. Chem. Process Des. Dev., 24, 581.

24. Radlein, D. and Quignard, A. 2013, Oil \& Gas Science and Technology - Rev. IFP Energies Nouvelles, 68(7), 765. 
25. Lindemuth, T. E. 1978, ACS Symposium Series; ACS: Washington, DC.

26. Li, C., Zheng, M., Wang, A. and Zhang, T. 2012, Energy Environ. Sci., 5, 6383.

27. Bosch, S. V., Schutyser, W., Koelewijn, S.F., Renders, T., Courtin, C. M. and Sels, B. F. 2015, Chem. Commun., 51, 13158.

28. Bosch, S. V., Renders, T., Kennis, S., Koelewijn, S.-F., Bossche, G. V., Vangeel, T., Deneyer, A., Depuydt, D., Courtin, C. M., Thevelein, J. M., Schutyser, W. and Sels, B. F. 2017, Green Chem., 19, 3313.

29. Xu, C. and Etcheverry, T. 2008, Fuel, 87, 335.

30. Jogi, R., Mäki-Arvela, P., Virtanen, P., Kumar, N., Hemming, J., Smeds, A., Lestander, T. A. and Mikkola, J-P. 2019, J. Chem. Technol. Biotechnol., 94, 3736.

31. Beauchet, R., Pinard, L., Kpogbemabou, D., Laduranty, J., Lemee, L., Lemberton, J. L., Bataille, F., Magnoux, P., Ambles, A. and Barbier, J. 2011, Bioresour. Technol., 102, 6200.

32. Araya, P. E., Droguett, S. E., Neuburg, H. J. and Badilla-Ohlbaum, R. 1986, Can. J. Chem. Eng., 64, 775.

33. Schutyser, W., Bosch, S. V., Renders, T., De Boe, T., Koelewijn, S.-F., Dewaele, A., Ennaert, T., Verkinderen, O., Goderis, B., Courtin, C. M. and Sels, B. F. 2015, Green Chem., 17, 5035.

34. Ferrini, P. and Rinaldi, R. 2014, Angew. Chem. Int. Ed., 53, 8634.

35. Ouyang, X., Huang, X., Zhu, J., Boot, M. D. and Hensen, E. J. M. 2019, ACS Sust. Chem. Eng., 7, 13764.
36. Cao, Z., Dierks, M., Clough, M. T., Castro, I. B. D. and Rinaldi, R. 2018, Joule, 2, 1118.

37. Renders, T., Schutyser, W., Bosch, S. V., Koelewijn, S-F., Vangeel, T., Courtin, C. M. and Sels, B. F. 2016, ACS Catal., 6, 2055.

38. Rautiainen, S., Francesco, D. D., Katea, S. N., Westin, G., Tungasmita, D. N. and Samec, J. S. M. 2019, ChemSusChem, 12, 404.

39. Liu, Y., Chen, L., Wang, T., Zhang, Q., Wang, C., Yan, J. and Ma, L. 2015, ACS Sust. Chem. Eng., 3, 1745.

40. Harmsen, P. F. H., Huijgen, W. J. J., López, L. M. B. and Bakker, R. R. C. 2010, ECNE-10-013.

41. Chaturvedi, V. and Verma, P. 2013, Biotech, 3, 415.

42. Klein, I., Marcum, C., Kenttämaa, H. and Abu-Omar, M. M. 2016, Green Chem., 18, 2399.

43. Zhao, C., Kou, Y., Lemonidou, A. A., Li, X. and Lercher, J. A. 2009, Angew. Chem. Int. Ed., 48, 3987.

44. Huang, X., Zhu, J., Koranyi, T. I., Boot, M. D. and Hensen, E. J. M. 2016, ChemSusChem, 9, 3262.

45. Huang, X., Gonzalez, O. M. M., Zhu, J., Korányi, T. I., Boot, M. D. and Hensen, E. J. M. 2017, Green Chem., 19, 175.

46. Guo, T., Li, X., Liu, X., Guo, Y. and Wang, Y. 2018, ChemSusChem, 11, 2758.

47. Zakzeski, J., Bruijnincx, P. C. A., Jongerius, A. L. and Weckhuysen, B. M. 2010, Chem. Rev., 110, 3552. 